\title{
Hopping conductivity of metal-dielectric nanocomposites produced by means of magnetron sputtering with the application of oxygen and argon ions
}

\author{
P. Żukowski ${ }^{a}$, T. Kołtunowicz ${ }^{\text {a,* }}$, J. Partyka ${ }^{\text {a }}$, Yu.A. Fedotova ${ }^{\text {b }}$, A.V. Larkin ${ }^{\mathrm{c}}$ \\ ${ }^{a}$ Lublin University of Technology, 38a Nadbystrzycka St., 20-618 Lublin, Poland \\ ${ }^{\mathrm{b}}$ National Center of Particles and High Energy Physics of BSU, 153 Bogdanovich St., 220040 Minsk, Belarus

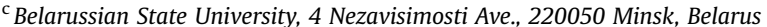

\section{A R T I C L E I N F O}

\section{Article history:}

Received 16 June 2008

Received in revised form

16 January 2009

Accepted 30 January 2009

\section{Keywords:}

Ion-beam sputtering

Granular nanocomposites

Percolation

AC conductance

Hopping conductance

\begin{abstract}
A B S T R A C T
Testing of electrical properties of nanocomposites $\left(\mathrm{Co}_{0,45} \mathrm{Fe}_{0,45} \mathrm{Zr}_{0,1}\right)_{x}+\left(\mathrm{Al}_{2} \mathrm{O}_{3}\right)_{1+x}$ within the concentration range of $0.30<x<0.65$, produced by means of magnetron sputtering of a target composed of stripes of metallic alloy and dielectric, has been carried out. It has been found that the studied materials contain metallic nanoparticles of a diameter ranging from 6 to $10 \mathrm{~nm}$. Alternating current conduction at $x<0.50$ is realized by hopping mechanism while at $x>0.50$ metallic conductivity is observed.

The obtained results have been analyzed using a model of hopping conductivity in the egime developed earlier. This analysis allowed to extract dependences of activation energy $\Delta E_{\tau}$ and times $\tau$ in a hopping regime after isochronous ( $15 \mathrm{~min}$ ) thermal annealings within the range from $293 \mathrm{~K}$ to $673 \mathrm{~K}$.
\end{abstract}

(c) 2009 Elsevier Ltd. All rights reserved.

\section{Introduction}

In our previous paper [1] we studied frequency (50-1 MHz) and temperature $(80 / 303 \mathrm{~K})$ dependences of $A C$ conductivity in the $\left(\mathrm{Co}_{0,45} \mathrm{Fe}_{0,45} \mathrm{Zr}_{0,1}\right)_{x}+\left(\mathrm{Al}_{2} \mathrm{O}_{3}\right)_{1+x}$ nanocomposites within the concentration of metallic phase in the range of $0.30<x<0.65$, produced by means of ion-beam sputtering of a complex target (composed of metallic alloy base and dielectric stripes) in $\mathrm{Ar}$ ambient The influence of isochronous $30 \mathrm{~min}$ annealings at temperatures from 423 to $623 \mathrm{~K}$ with a step of $50 \mathrm{~K}$ was also studied. As follows the initial (as-deposited) samples display weak frequency dependences of real part of AC conductivity $\sigma_{\text {real }}(f)$ at most temperatures. It was also observed that $\sigma_{\text {real }}(T)$ dependences at low frequencies followed the activational law before the percolation threshold $x_{C}$ and metallic one beyond the $x_{C}$. With the increase of annealing temperatures $T_{\mathrm{ann}}$, frequency dependences of $\sigma_{\text {real }}$ enhanced and acquired S-shaped character. These experimental results were analyzed on the basis of the hopping AC/DC conductivity model proposed in [2] and developed in more details in [3].

\footnotetext{
* Corresponding author.

E-mail address: t.koltunowicz@pollub.pl (T. Kołtunowicz).
}

This model proposes that an external alternating electric field is weak and does not change the probability of electron jump $p(N, T$, $\Delta E$ ) which is dependent on concentration of potential wells $N$, temperature $T$ and energy of hopping activation $\Delta E$. In the case of tunnelling regime, the $p$ values also depend on the rate for the electrons wave function dropping. Then the jump electron is localized in a well during time $\tau$ whereupon it can perform the next jump either in the line of electric field (with probability $p$ ) or against it (with probability $(1-p)$ ). Taking into account that there is distribution of wells by life times $F\left(\tau_{\mathrm{m}}, \Delta\right)$ [4], where $\Delta$ is the standard deviation, the active part of alternating current density is equalled by

$j_{\mathrm{a}} \sim E_{0} \sin \omega t \int_{0}^{\infty} F\left(\tau_{\mathrm{m}}, \Delta\right)[1-(1-2 p)] \cos \omega \tau d \tau$,

where $E=E_{0} \sin \omega t$ is the electric intensity and $\omega=2 \pi f, \tau_{\mathrm{m}}$ - the mean lifetime of electron in a well and $\Delta-$ its standard deviation.

The analysis of Eq. (1) shows that for the region of low frequencies (direct current) $j_{\mathrm{a}}$ values follow the relation

$j_{\mathrm{a} 0} \sim 2 p E_{0} \sin \omega t$

and for high frequencies

$j_{\mathrm{a} \infty} \sim E_{0} \sin \omega t$. 
This means that the $p$ value can be extracted from the experimental $\sigma_{\text {real }}(f)$ dependencies:

$p=\frac{\sigma_{\text {real }}(f \rightarrow 0)}{2 \sigma_{\text {real }}(f \rightarrow \infty)}$.

In our previous works [2,3] we used normal distribution of $\tau$. However, from a physical point of view, it is reasonable to use distribution only for the positive values of $\tau$, for example, the distribution of the extreme value [5] or the Landau distribution in the Moyal approach [6]. In this work we used the Landau distribution.

The goal of this work was to investigate the temperaturefrequency dependencies of AC conductivity of nanocomposites
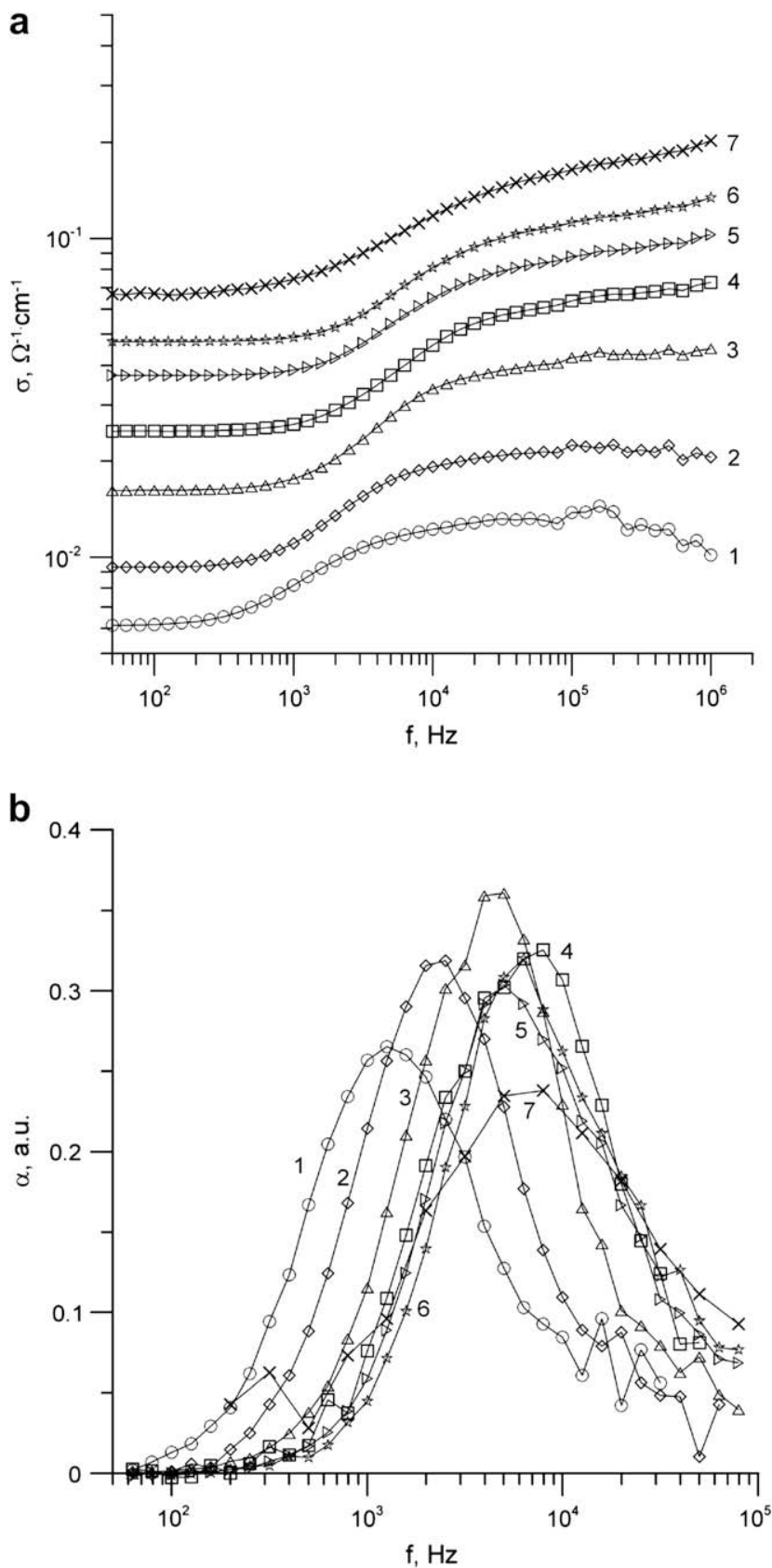

Fig. 1. $\sigma_{\text {real }}(T, f)$ dependences $(a)$ and $\alpha$ values $(b)$ for the as-deposited sample with $x \approx 42.6$ at.\% at different measurement temperatures: $1-T=79 \mathrm{~K} ; 2-103 \mathrm{~K}, 3-$ $133 \mathrm{~K}, 4-163 \mathrm{~K}, 5-193 \mathrm{~K}, 6-223 \mathrm{~K}$ and $7-283 \mathrm{~K}$.
$\left(\mathrm{Co}_{0,45} \mathrm{Fe}_{0,45} \mathrm{Zr}_{0,1}\right)_{x}+\left(\mathrm{Al}_{2} \mathrm{O}_{3}\right)_{1+x}$, deposited either in the $\mathrm{Ar}+\mathrm{O}_{2}$ gas ambient and check the AC/DC model developed in [2,3].

\section{Experimental}

The $\left(\mathrm{Co}_{45} \mathrm{Fe}_{45} \mathrm{Zr}_{10}\right)_{x}\left(\mathrm{Al}_{2} \mathrm{O}_{3}\right)_{1-x}$ films of 3 to $5 \mu \mathrm{m}$ thick were prepared by ion-beam sputtering in a chamber evacuated with $\mathrm{Ar}+\mathrm{O}_{2}$ gas mixture at total pressure of $6.7 \cdot 10^{-2} \mathrm{~Pa}$ and with a partial pressure $P_{0}=(1.3-5.0) \cdot 10^{-3} \mathrm{~Pa}$. A special construction of compound target allowed getting the film with a wide region of metal-to-dielectric ratios $x(31 \leq x \leq 64$ at.\%) on the class ceramic substrate in one deposition procedure [7].

Measurements of AC conductance $\sigma$ and lagging tag have been performed for the frequencies $f$ between $50 \mathrm{~Hz}$ and $1 \mathrm{MHz}$ at the
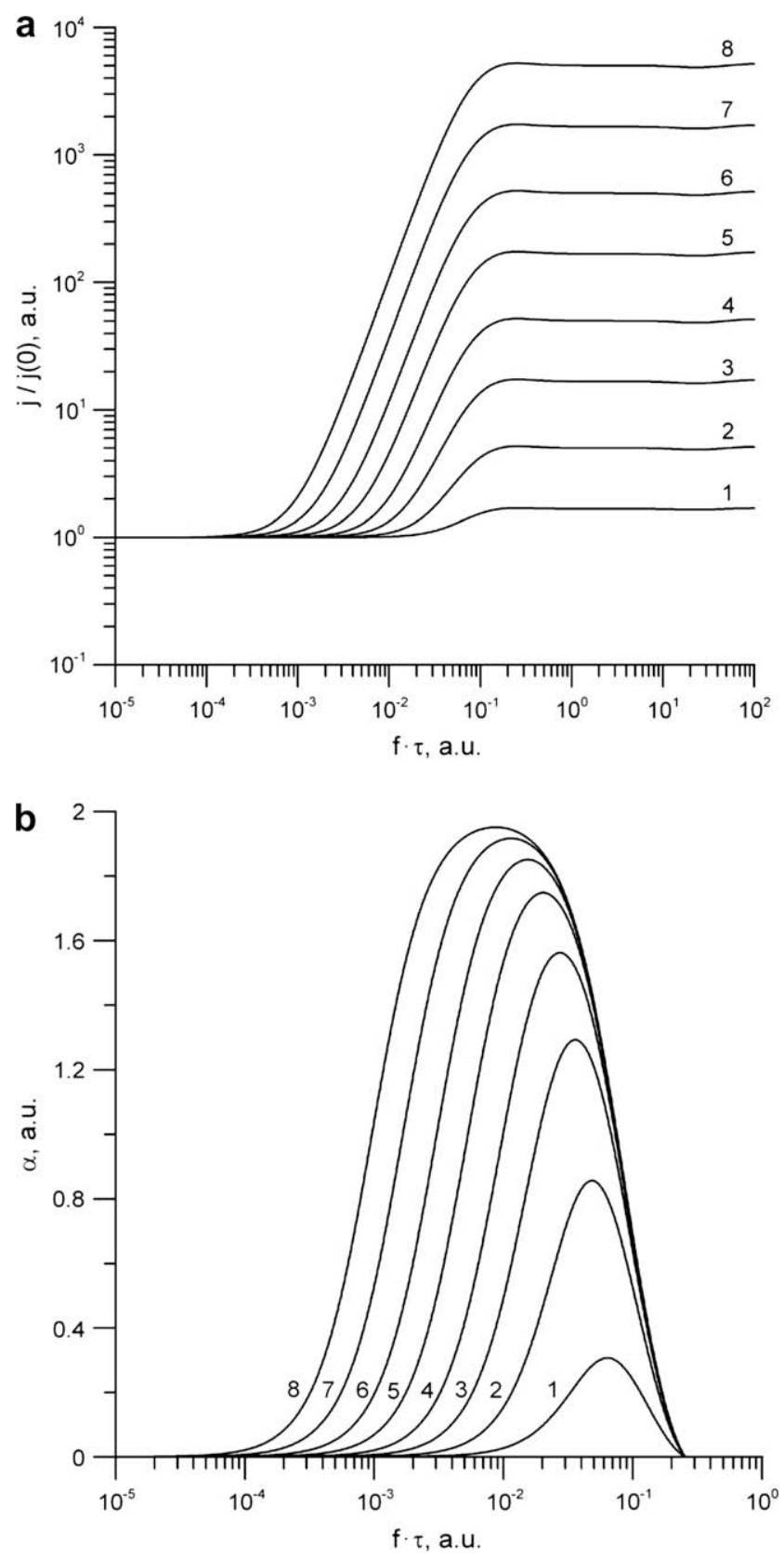

Fig. 2. Frequency dependencies of $\sigma_{\text {real }}(a)$ and the exponent $\alpha(b)$ calculated by Eq. (1) for different probability $p$ values: $1-p=0.3,2-0.1,3-0.03,4-0.01,5-0.003,6-$ $0.001,7-0.0003$ and $8-0.0001$ at using of Landau distribution [6]. 
temperatures $T$ from $79 \mathrm{~K}$ to $373 \mathrm{~K}$ for the samples in the initial (as-deposited) state as well as directly after their isochronous (15 min) annealings in a tubular furnace within the temperature range from $398 \mathrm{~K}$ to $673 \mathrm{~K}$ with the $25 \mathrm{~K}$ step. This procedure was described in more details in [8].

Preliminary investigations of the studied nanocomposites in the as-deposited state have revealed that their phase structure and carrier transport properties were dependent on metal-to-dielectric ratios $x$ and strongly changed with the addition of oxygen into gas ambient [1,3,9-11]. In particular, for the films deposited in pure Ar gas before the percolation threshold $\left(x<x_{C} \approx 45-47\right.$ at.\%) nanocomposites showed the superparamagnetic state whereas beyond $x_{\mathrm{C}}$ they were in the ferromagnetic state. Moreover, it was proved that the mechanism of electron transport in the films was changed from hopping process by localized states in the dielectric $\mathrm{Al}_{2} \mathrm{O}_{3}$ matrix to metallic one when crossing the $x_{C}$. Mössbauer study has shown that in the films sputtered in the $\mathrm{Ar}-\mathrm{O}_{2}$ gas mixture, the presence of oxygen resulted in partial oxidation of metallic Nan particles and conservation of superparamagnetic state of the samples even beyond the $x_{\mathrm{C}}$. Moreover, the DC measurements on such samples revealed only hopping regime of conductance for the whole range of $x$.

\section{Results and discussion}

The results of temperature-frequency dependences for real part of AC conductivity $\sigma_{\text {real }}(T, f)$ of the as-deposited films studied are shown in Fig. 1 for the sample with $x \approx 42.6$ at.\%. The results for the $\sigma_{\text {real }}(T, f)$ and their analysis for the films deposited in pure Ar atmosphere are discussed in the other paper [12].

As can be seen in Fig. $1 a$, the $\sigma_{\text {real }}(f)$ progress in the initial film is of $\mathrm{S}$-shaped character and can be described by the relation which is characteristic of hopping conductance [13]

$\sigma_{\text {real }}(f) \approx \sigma_{0} f^{\alpha}$,

where $\sigma_{0}$ is the coefficient and the exponent $\alpha$ depends on the mechanism of hopping conductance (in particular, on the above mentioned probability $p$ ). Note that the exponent $\alpha$ has maximum in an inflection point of S-shaped part of $\sigma_{\text {real }}(f)$ curves (see, Fig. $1 b$ ).

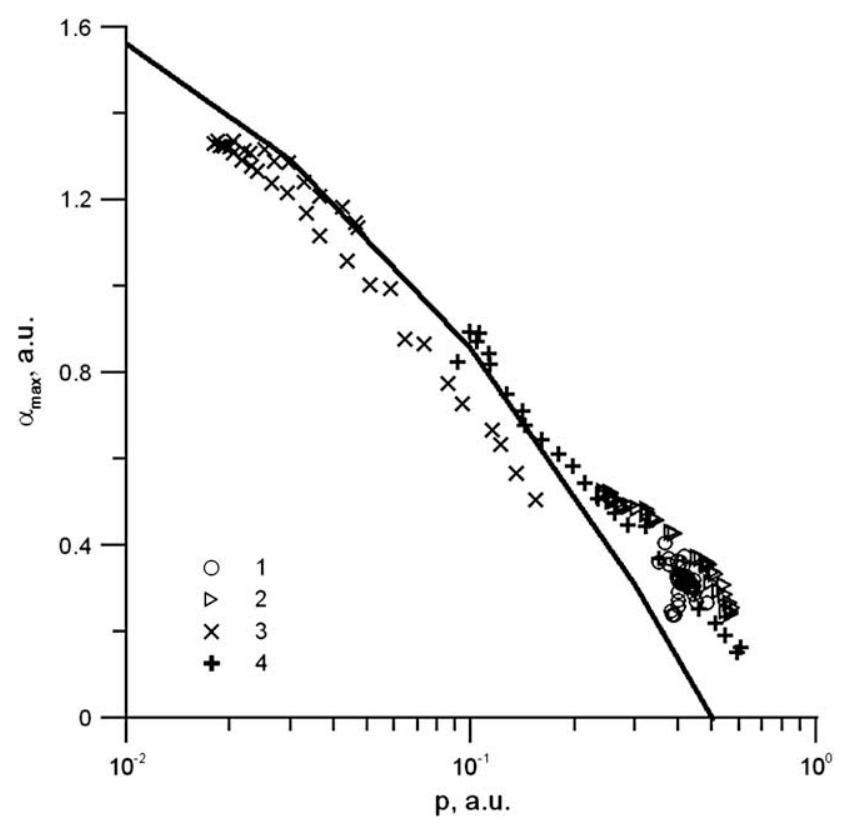

Fig. 3. Calculated (solid line) and experimental (points) dependences of $\alpha_{\max }(p)$. Experimental values of $\alpha_{\max }$ are extracted from $\sigma_{\text {real }}(f)$ dependences for the initial sample (1) and after annealings at $T_{\mathrm{ann}}=473 \mathrm{~K}(2), 548 \mathrm{~K}(3), 548 \mathrm{~K}(4)$.
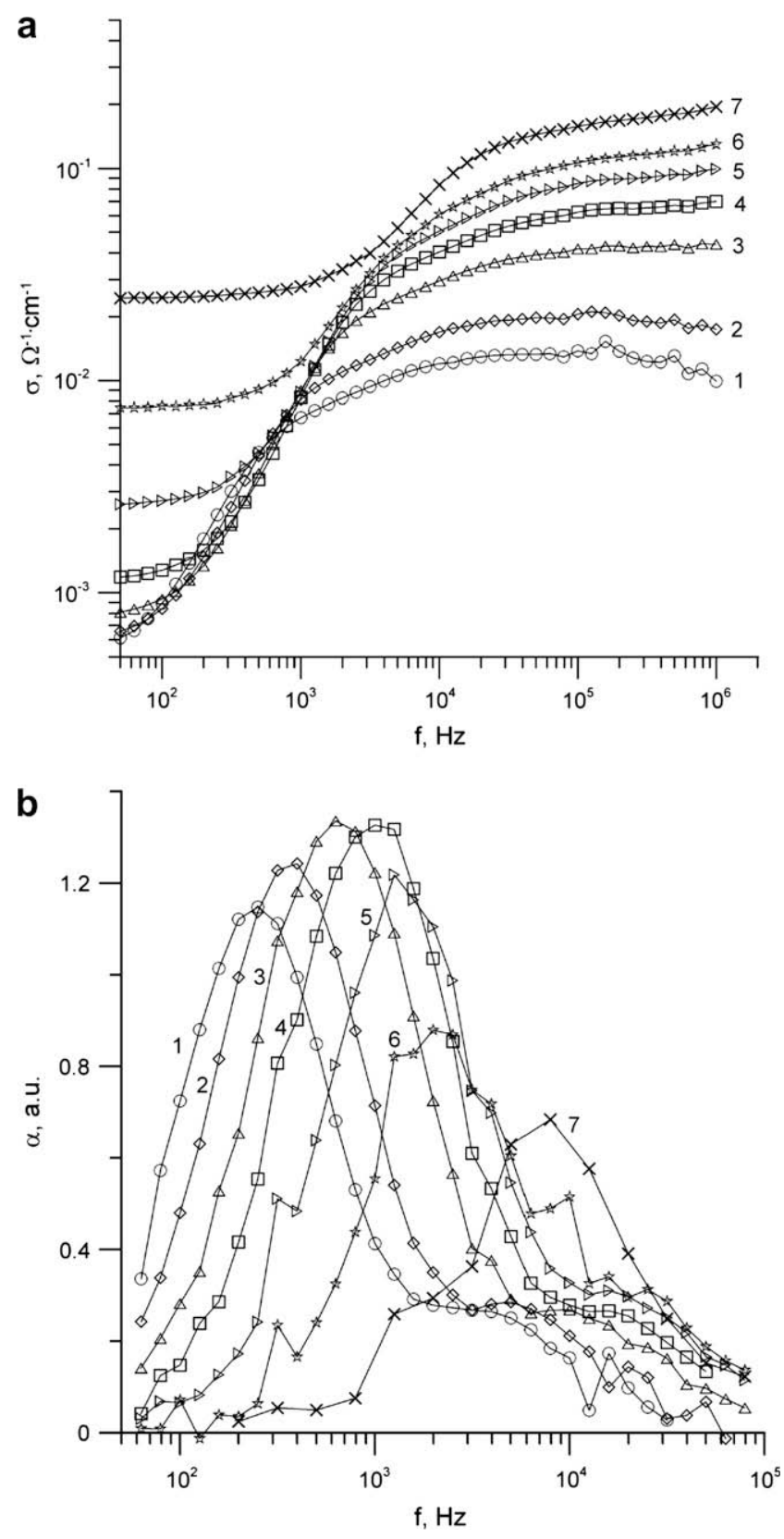

Fig. 4. Frequency dependencies of $\sigma_{\text {real }}(\mathrm{a})$, measured at the same temperatures as in Fig. $1 a$, and estimated $\alpha$ (b) for the sample with $x=42.6$ at.\% after annealing at $T_{\text {ann }}=548 \mathrm{~K}$.

Computer simulation on the basis of Eq. (1) allows to estimate the $\sigma_{\text {real }}(f)$ dependencies and the values of $\alpha$ for different magnitudes of probability $p$. The results of these simulations are shown in Fig. 2. Comparison of the experimental dependencies of $\sigma_{\text {real }}(f)$ and $\alpha_{\max }(f)$, shown in Fig. $1 a$ and $b$ correspondingly, with the results of their computer simulation has revealed good qualitative agreement. As can be seen in Fig. $2 b$, the value of $\alpha_{\max }(f)$ is a function of probability $p$. The calculated $\alpha_{\max }(p)$ dependence is shown by unbroken line in Fig. 3. Here we also bring the experimental value of $\alpha_{\max }(p)$ estimated for different temperatures of measurements and after annealings at different $T_{\text {ann }}$ which also shows good quantitative agreement between experiments and estimations.

As follows from the analysis of $\alpha_{\max }(p)$, annealing at $523 \mathrm{~K}$ results in essential enhancement of $\sigma_{\text {real }}(f)$ dependencies and increase of $\alpha_{\max }$ values (Fig. $4 a$ and $b$ ). We can see that the $\alpha(f)$ 
curves approach their maximal values close to 1.3 at low temperatures, and at high temperature the second, weakly-defined maximum is observed in the region of high frequencies $(\sim 10 \mathrm{kHz})$. The value of the latter is compared with that observed after lowtemperature annealings.

It is necessary to note that after low-temperature annealings the values of probabilities $p$ are situated in the region of $0.35 \pm 0.15$ that corresponds to jumps of electrons from the neutral impurities (defects) to the charged ones. This means that in the as-deposited sample there are a lot of localized centers (metallic atoms or other defects in dielectric matrix) by which electron hopping is carried out. With the increasing $T_{\mathrm{ann}}$ some diffusion processes are enhanced resulting in the change of density of the localized states (DOS) in the alumina matrix. This can be realized due to two possible mechanisms: (i) migration of metallic atoms fragmented in the alumina matrix to metallic nanoparticles and their enlargement [12] as well as (ii) completion of dangling bonds presented in the amorphous alumina. Both these processes should result in decrease of DOS and therefore reduction of $\sigma_{\text {real }}$ at the lowest temperatures of measurements $(79 \mathrm{~K})$ - compare Figs. $1 a$ and $4 a$. Simultaneously, in the low-frequency range, part of growth in the $\sigma_{\text {real }}(f)$ dependence appears which is characterized by the highest $\alpha_{\max }$ values close to $1.2 / 1.3$ (compare Figs. $1 b$ and $4 b$ ).

Such high values of $\alpha_{\max }$ realized after annealings at $T_{\mathrm{ann}}>523 \mathrm{~K}$ indicate that the carrier transport is executed by overbarrier migration mechanism rather than by underbarrier tunnelling [13]. These barriers can arise due to diffusion of oxygen atoms incorporated into the film during their deposition (see, backscattering spectra in [12]) to metallic nanoparticles and additional oxidation.

The presence of low maximum on the curves $\alpha(f)$ at $f \sim 10 \mathrm{kHz}$ after high-temperature annealings probably testifies that not all metallic atoms migrate from the matrix to the metallic nanoparticles.

\section{Conclusion}

The analysis of temperature-frequency dependencies of $\mathrm{AC}$ electrical conductivity in $\left(\mathrm{Co}_{0,45} \mathrm{Fe}_{0,45} \mathrm{Zr}_{0,1}\right)_{x}+\left(\mathrm{Al}_{2} \mathrm{O}_{3}\right)_{1+x}$ nanocomposites below the percolation threshold (with $x=42.6$ at.\%), deposited in $\mathrm{Ar}+\mathrm{O}_{2}$ ambient, before and after isochronous (15 min) annealings within the temperature range from $398 \mathrm{~K}$ to $648 \mathrm{~K}$ allows to make the following conclusions:
1. In the initial (as-deposited) samples and also after their lowtemperature $(523 \mathrm{~K})$ annealings the hopping carrier transport is carried out by DOS in the alumina matrix (metallic atoms or other defects). The influence of metallic nanoparticles in this process is insignificant.

2. After high-temperature annealings at $T_{\mathrm{ann}}>523 \mathrm{~K}$ part of metallic and oxygen atoms diffuses to nanoparticles creating additional barriers at their surface. This results in $\sigma_{\text {real }}$ decrease in the low-frequency range and at the lowest temperatures ( $79 \mathrm{~K})$ and enhances the $\sigma_{\text {real }}(f)$ dependences in accordance with the law $\sigma_{\text {real }}(f) \sim f^{\alpha}$. In such a case, the values of $\alpha_{\max }$ approach 1.2-1.3 that is the evidence for overbarrier jumps of electrons.

3. Very good qualitative and quantitative agreement between the experimental and the computer simulation results for the developed model of hopping carrier transport in the DC/AC regimes is established.

\section{Acknowledgement}

The authors would like to acknowledge the financial support from VISBY Program of the Swedish Institute.

\section{References}

[1] Żukowski P, Kołtunowicz T, Partyka J, Węgierek P, Fedotova JA, Fedotov AK, et al. Electrical Review 2008;84(3):244-6.

[2] Zukowski P, Koltunowicz T, Partyka J, Wegierek P, Komarov FF, Mironov AM, et al. Vacuum 2007;81:1137-40.

[3] Żukowski P, Kołtunowicz T, Partyka J, Węgierek P, Kolasik M, Larkin AV, et al. Electrical Review 2008;84(3):247-9.

[4] Žukowski PV, Partyka J, Wegierek P, Shostak Yu, Sidorenko Yu, Rodzik A. Semiconductors 2000;34:1124-7.

[5] Statistical methods in experimental physics. Moscow: Atomizdat; 1976.

[6] Nowak R. Statystyka dla fizyków. Warszawa: PWN; 2002.

[7] Yu Kalinin, Remizov A, Sitnikov A. Solid State Physics 2004;4:2076-82.

[8] Kołtunowicz T. Elektronika - konstrukcje, technologie. Zastosowania 2007;10:37-40.

[9] Fedotova J, Kalinin Yu, Fedotov A, Sitnikov A, Svito I, Zalesskij A, et al. Hyperfine Interaction 2005;165:127-34.

[10] Saad AM, Fedotov AK, Fedotova JA, Svito IA, Andrievsky BV, Kalinin YuE, et al. Physica Status Solidi (C) 2006:3:1283-90.

[11] Saad AM, Fedotov AK, Svito IA, Mazanik AV, Andrievski BV, Patryn AA, et al. Progress in Solid State Chemistry 2006;14:139-46.

[12] Żukowski P, Kołtunowicz T, Partyka J, Fedotova YuA, Fedotov AK, Larkin AV. Vacuum 2009;83:S275-9.

[13] Mott NF, Davies EA. Electronic process in non-crystalline materials. Oxford: Clarendon Press; 1979 